\title{
To Determine The Frequency Of Vitamin D Deficiency In Patients With Chronic Hepatitis C
}

Imran Hussain, M. Zill-e-Humayun Mirza, Ali Yusuf

\section{ABSTRACT}

Objective: To determine the frequency of vitamin D deficiency in patients with chronic hepatitis $\mathrm{C}$ (CHC)

Design: It was a Descriptive and Cross Sectional study

Place and Duration of Study: It was carried out in the Medicine Unit of Pakistan Naval Ship SHIFA, Karachi from Nov 29, 2016 to May 29, 2017.

Patients and Methods: Approval was sought from Institutional Review Board before carrying out the study. Proper history, clinical examination and appropriate lab investigations were carried out. Standard techniques were used for blood sample collection. Site used for blood collection was antecubital fossa. Sterile method was used for fasting sample and about $10 \mathrm{ml}$ of blood was collected from each patient.

Results: A total of 289 patients were included. Strict exclusion and inclusion criteria was used for study cohort. Mean age (years) of study cohort was 34.51+8.32. There were 188 (65.1) male and 101 (34.9) female patients. Patients with CHC who were vitamin D deficient were 74 (25.6).

Conclusion: Patients of CHC had high frequency of vitamin D deficiency which suggests that further studies in the region will be conduct in our general population to know the exact statistics which will pave the way for future researchers

Keywords: Chronic Hepatitis C, Vitamin D deficiency, Liver Cirrhosis.

- - - - - - - - - - - - - - - - - - - - - - - - - - - -

\section{INTRODUCTION:}

Hepatitis $\mathrm{C}$ infection is caused by hepatitis $\mathrm{C}$ virus (HCV), an RNA virus. It is an infectious disease and liver is the main target of this virus. Around $70 \%$ of the infected become chronic carrier. The most feared complication of hepatitis $\mathrm{C}$ infection is cirrhosis, which may take 10 to 20 years to develop, and affect about $30 \%$ of patients with $\mathrm{CHC}^{1}$. Complications of hepatic cirrhosis include jaundice, ascites, encephalopathy, gastro intestinal bleeding, gastric varices and bleeding profile disturbances. Hepatitis $\mathrm{C}$ infection is prevalent all over the world with highest burden in developing countries. It is a rising reason of mortality and morbidity due to the disease especially in low income countries ${ }^{2}$.

Vitamin D has multiple functions in the body. It is an important vitamin soluble in fat. Its central role is to increase the absorption of micronutrients from the gut like calcium, phosphate, zinc and magnesium. Many steps occur in the synthesis of vitamin $\mathrm{D}$ and each step is mediated by specific enzyme. In the liver the inactive form of vitamin D is

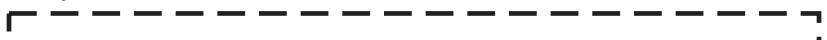

Imran Hussain,

Department of Medicine

I Resident, PNS Shifa Hospital

M. Zill-e-Humayun Mirza,

I Department of Medicine

I Classified Medical Specialist, PNS Shifa Hospital

I

Ali Yusuf,

Department of Medicine

I Classified Medical Specialist, CMH Quetta

Received: 01-08-2018

I Accepted: 08-10-2018

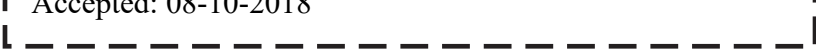

hydroxylated to its major form, the 25-hydroxyvitamin D $[25(\mathrm{OH}) \mathrm{D}]$. This is a measure of body vitamin $\mathrm{D} \mathrm{level}^{3}$. Further conversion of $25(\mathrm{OH}) \mathrm{D}$ to 1, 25-dihydroxyvitamin $\mathrm{D}[1,25(\mathrm{OH}) \mathrm{D}]$ occur in kidney and enzyme required for this reaction 1-alpha-hydroxylase. $[1,25(\mathrm{OH}) \mathrm{D}]$ formation mostly occur in the kidneys but the same vitamin is also formed in many other extra renal organs ${ }^{4}$. Vitamin receptors which are manifested in various organs are activated resulting in its action. Regulation of almost 3\% of the human genome is done by active vitamin D. Its role is not only in micronutrients homeostasis but has also been recognized as a vital physiological regulator with pleiotropic functions ${ }^{5}$. In addition to bone diseases vitamin D insufficiency has been associated with a higher incidence of cancer $^{6}$, cardiovascular ${ }^{7}$, infectious diseases like hepatitis $\mathrm{C}$ and autoimmune disorders ${ }^{8,9}$. Sun exposure is important for optimum vitamin D level. Though in Pakistan sun exposure is almost optimal but still vitamin D deficiency is most prevalent in this part of the world, which may be due to so many reason ${ }^{10}$. Many studies highlighted that patients with Chronic Hepatitis C have concomitant vitamin D deficiency ${ }^{11}$. However there is a significant variation regarding it's frequency in $\mathrm{CHC}$ patients, varying from $4 \%$ to $92 \%{ }^{12}$. Furthermore there is a controversy in classifying serum vitamin $\mathrm{D}$ levels as different upper and lower limits values were employed in different studies ${ }^{8}$.

Our study results will clarify the above variation in our target population and find out the frequency of vitamin D deficiency in our CHC cohort. The controversy in classifying circulating vitamin D levels will be addressed by using lower limit of $30 \mathrm{ng} / \mathrm{ml}$ of serum vitamin $\mathrm{D}$, as mentioned 
is some studies ${ }^{8}$. Our study will set a baseline data for our general population for frequency of vitamin D deficiency in patients with chronic hepatitis C. Results of our study will pave the way for future researchers to plan more research on this topic.

\section{PATIENTS AND METHODS:}

This Descriptive and Cross Sectional study was conducted in the Medicine Unit of Pakistan Naval Ship SHIFA, Karachi, from Nov 29, 2016 to May 29, 2017. Sample size (n) of 289 was calculated with the help of World Health Organization sample size calculator. Confidence level was kept at 95\%. Anticipated population proportion (P) was taken as $25 \%$ and absolute precision required (d) was kept at 5\%. Consecutive non-probability sampling technique was used for sampling. A cut of value of serum $25(\mathrm{OH}) \mathrm{D}$ less than $30 \mathrm{ng} / \mathrm{ml}$ was considered as a vitamin D deficiency (confirmed on laboratory investigations employing radioimmunoassay).

Patients of either gender with age 20-50yrs and Anti HCV positive patients (on laboratory investigation) at least of 6 months duration (on history and hospital record) and quantitative PCR detected for HCV RNA (on laboratory investigation) were included in the study. Already diagnosed cases of vitamin D deficiency (based on history and medical record), those under treatment of vitamin D deficiency (based on history and medical record), patients already on antiviral therapy (on history and medical record) and patients with concurrently Hep B sAg positive were excluded from the study.

Approval was sought from Institutional Review Board before carrying out the study. After proper history, clinical examination and lab investigations patients' written informed consent was documented. All data was anonymized to ensure confidentiality. Standard techniques were used for blood sample collection. Site used for blood collection was antecubital fossa. Sterile method was used for fasting sample and about $10 \mathrm{ml}$ of blood was collected from each patient. It was immediately transferred to a clean container with cap and sent to laboratory for analysis. All the specimen collections was done by $4^{\text {th }}$ year resident student. Data was recorded for vitamin $\mathrm{D}$ deficiency as per operational definition and noted on especially designed proforma (attached with).

For data analysis SPPS version 20 was used. For descriptive analyses like age, we calculated standard deviation and mean. For qualitative variables like gender and vitamin D deficiency in $\mathrm{CHC}$, frequency and percentages were calculated.

Confounders were controlled in analysis by stratification of data with regards to gender and age. After stratification, a Chi square test was used and $p$ value $=0.05$ was taken as significant.

\section{RESULTS:}

Total number of 289 patients was included in the study.
Mean age (years) was $34.51+8.32$ with ranges from 20 to 50 years. There were 188 (65.1) male and 101 (34.9) female patients. 74 (26) patients with $\mathrm{CHC}$ were having Vit D deficiency and rest of the 215(74) CHC patients were not deficient as shown in table 1. Effect modifier like gender stratification was compared with deficiency of vitamin-D in chronic hepatitis $C$ patients. There were 51 (68.9) male and 23 (31.1) female patients who had the deficiency in chronic hepatitis $\mathrm{C}$ patients, as depicted in Table. 2. Effect modifier like age stratification was compared with deficiency of vitamin-D in chronic hepatitis $\mathrm{C}$ patients. There were 18 (24.3) and 56 (75.1) patients between age $20-30$ years and $31-50$ years respectively, who had the deficiency in chronic hepatitis $\mathrm{C}$ patients, as depicted in Table. 3.

\begin{tabular}{|l|c|c|}
\hline & Frequency & Percentage \\
\hline Yes & 74 & 25.6 \\
\hline No & 215 & 74.4 \\
\hline Total & 289 & 100.0 \\
\hline
\end{tabular}

Table. 1 Frequency \& percentage of deficiency of Vitamin$\mathrm{D}$ in chronic hepatitis $\mathrm{C}$ patients

\begin{tabular}{|l|l|l|l|}
\hline \multirow{2}{*}{ Gender } & \multicolumn{2}{|c|}{$\begin{array}{l}\text { Vitamin-D deficiency in } \\
\text { chronic hepatitis C patients }\end{array}$} & \multirow{2}{*}{ p-value } \\
\cline { 2 - 3 } & Yes & No & \\
\hline Male & $51,68.9 \%$ & $137,63.7 \%$ & \multirow{2}{*}{0.419} \\
\cline { 2 - 3 } Female & $23,31.1 \%$ & $78,36.3 \%$ & \\
\hline Total & $74,100.0 \%$ & $215,100.0 \%$ & \\
\hline
\end{tabular}

Table. 2 Effect modifier like gender stratification with deficiency of vitamin-D in chronic hepatitis $\mathrm{C}$ patients

\begin{tabular}{|c|c|c|c|}
\hline \multirow{2}{*}{$\begin{array}{c}\text { Age } \\
\text { Cohorts }\end{array}$} & \multicolumn{2}{|c|}{$\begin{array}{c}\text { Vitamin-D deficiency in } \\
\text { chronic hepatitis C patients }\end{array}$} & p-value \\
\cline { 2 - 3 } & Yes & No & \\
\hline $20-30$ (years) & $18,24.3 \%$ & $66,30.7 \%$ & \multirow{2}{*}{0.298} \\
\hline $31-50$ (years) & $56,75.7 \%$ & $149,69.3 \%$ & \\
\hline Total & $74,100.0 \%$ & $215,100.0 \%$ & \\
\hline
\end{tabular}

Table 03 Effect modifier like age group stratification with deficiency of vitamin-D in chronic hepatitis $\mathrm{C}$ patients

\section{DISCUSSION:}

Skin, kidneys and liver play a pivotal role in vitamin D synthesis. For its physiological effects, vitamin D receptors (VDR) are to be present. Interaction of vitamin D with VDR then activates several pathways which then play important roles. Different steps of inflammation, immune response and fibrosis are mediated by vitamin $\mathrm{D}$ activated pathways. Also it has been found to be liver protective ${ }^{13}$. VDR are presents on liver cells, inflammatory cells and biliary tract cells. But with advanced hepatic fibrosis its expression is reduced $^{13}$. Deficiency of Vitamin D has been found in both, cirrhotic and chronic liver disease patients. These cohorts have also been found to have high mortality. Due to this 
fact researchers are trying to find a relation between chronic live disease and vitamin $\mathrm{D}$ level. The most common etiological agent of chronic liver disease and cirrhosis in Pakistan is hepatitis $\mathrm{C}^{14}$; therefore we carried out this study to look for vitamin $\mathrm{D}$ level in these patients. The findings of our study also show many of the chronic hepatitis $\mathrm{C}$ patients, who were also vitamin $\mathrm{D}$ deficient.

Ribavirin (RBV) and Pegylated interferon (PEG-IFN) are used to treat $\mathrm{HCV}$ infection. The duration of treatment depend on the type of HCV. For genotype 1, the 48 weeks and for genotypes 2 and 3, 24 weeks treatment is recommended. The main aim of treatment for $\mathrm{HCV}$ infection is to clear the virus from the blood, and that after the treatment; undetectable serum HCV RNA level is sustained. This is what is called sustained virologic response (SVR). Among the subtypes, Genotypes 2 and 3 have better response to therapy and the SVR rates approaches up to $70 \%$. Patient with genotype 1 have poor response to conventional treatment and its SVR rate is up to $50 \%$. Most recent studies are searching for metabolic and genetic factors which may influence the response to treatment. However, results of these are inconclusive $e^{15}$. But still in recent literature, like our study, patients having chronic hepatitis $\mathrm{C}$ have been found to be deficient in vitamin $\mathrm{D}$, and hence vitamin $\mathrm{D}$ supplementation to standard therapy of hepatitis $\mathrm{C}$ has been suggested ${ }^{5}$.

It has been seen that in patients with chronic hepatitis $\mathrm{C}$, disease outcome is affected by patient's vitamin $\mathrm{D}$ level and most of the patients with chronic hepatitis $\mathrm{C}$ were found to be deficient in vitamin D. A large multi centered study, carried out in Sicily, revealed that patients with CHC infections have vitamin D levels lower, as in comparison to age and sex matched healthy cohort. Level of Vitamin D was less than $30 \mathrm{ng} / \mathrm{ml}(43.1 \pm 10.2 \mathrm{ng} / \mathrm{ml})$ in $6 \%$ of the healthy population, whereas in chronic hepatitis $\mathrm{C}$, more than $70 \%$ were found to be deficient in vitamin $\mathrm{D}(25.1 \pm 9.9 \mathrm{ng} / \mathrm{ml})$. This difference was statistically significant $(p<0.0001)^{16}$. In contrast, in our study only $25 \%$ patient with chronic hepatitis $\mathrm{C}$ had deficiency of vitamin D. How does this low level of vitamin $\mathrm{D}$ affect disease response and outcome in patients of $\mathrm{CHC}$ is still not yet clear. Few possible mechanisms have been suggested. In some recent literature it has been opined that hepatitis $\mathrm{C}$ virus interferes with metabolism of lipids, thus resulting in low vitamin D level; 7-dehydrocholesterol which is a vitamin D precursor, its synthesis is blocked by hepatitis $\mathrm{C}$ virus. Also more recent studies have pointed out that the more severe the deficiency of vitamin $\mathrm{D}$ in chronic liver disease; the more grave its complications are ${ }^{17}$.

A Spanish study enrolled 108 chronic hepatitis $C$ cases, and found that $36 \%$ of the study population was vitamin D deficient. Whereas in our study total patients were 289 and $25 \%$ patients out of these were vitamin D deficient. In their study found that the mean age in years was $52.2 \pm 9.0$. Whereas in our study mean age in years was $34.51+8.32$.
Similar to our study most of the patient population was male. They concluded that vitamin D supplementation in study population corrected vitamin D level but it had no effect on biochemical profile and treatment response. They have larger percentage of study population with vitamin D deficiency as compared to our study. This difference may be due to variation in geographic area. Also they carried out the study in winter season at which time there is little sun exposure. This might have added to larger number patient being vitamin $\mathrm{D}$ deficient ${ }^{18}$.

Most recent literature has stated that around $60 \%$ of the chronic hepatitis $\mathrm{C}$ cases have vitamin $\mathrm{D}$ hypo-vitaminosis in most part of the world including USA and Asians countries. In our study it was $25 \%$. Also it has been found that vitamin $\mathrm{D}$ is having antiviral activity and that it directly suppress hepatitis C viral replication. Similarly in contrast to previous studies it has been proved that vitamin D supplementation also improve SVR with little additional adverse effects and $\operatorname{cost}^{19}$.

There are few limitations of our study. It was a single centered study. We did not study patients' treatment response with and without vitamin D supplementation. We did not investigate the effect of vitamin $\mathrm{D}$ addition, on biochemical profile and sustained viral response (SVR). It is therefore recommend that multi centered study on larger scale are required to be carried out. Also vitamin D effect on SVR is to be studied.

\section{CONCLUSION:}

Patients of CHC had high frequency of vitamin D deficiency which suggests that further studies in the region will be conducted in our general population to know the exact statistics which will lead the way for enthusiastic researchers to plan more researches in this domain to prevent hepatitis $\mathrm{C}$ virus related diseases in the region.

\section{REFERNCES:}

1. Elgharably A, Gomaa AI, Crossey MM, Norsworthy PJ, Waked I, Taylor-Robinson SD. Hepatitis C in Egypt-past, present, and future. International journal of general medicine. 2017; 10:1.

2. Waheed Y. Hepatitis C eradication: a long way to go. World J Gastroenterol. 2015; 21(43):12510-2.

3. Fleet JC, DeSmet M, Johnson R, Li Y. Vitamin D and cancer: a review of molecular mechanisms. Biochem J. 2012; 441(1):61-76.

4. Haines ST, Park SK. Vitamin D supplementation: what's known what to do, and what's needed. Pharmacotherapy. 2012; 32(4):354-82.

5. Rahman AH, Branch AD. Vitamin D for your patients with chronic hepatitis C? J Hepatol. 2013; 58(1):184-9.

6. Lappe J, Watson P, Travers-Gustafson D, Recker R, Garland C, Gorham E, Baggerly K, McDonnell SL. Effect of vitamin $\mathrm{D}$ and calcium supplementation on cancer incidence in older women: a randomized clinical trial. Jama. 2017; 317(12):123443. 
7. Mozos I, Marginean O. Links between vitamin D deficiency and cardiovascular diseases. BioMed research international. $2015 ; 2015$.

8. Villar LM, Del-Campo JA, Ranchal I, Lampe E, RomeroGomez M. Association between vitamin D and hepatitis C virus infection: a meta-analysis. World J Gastroenterol. 2013; 19(35):5917-24.

9. Roomi MA, Farooq A, Ullah E, Lone KP. Hypovitaminosis $\mathrm{D}$ and its association with lifestyle factors. Pak J Med Sci. 2015; 31(5):1236-40. doi: 10.12669/pjms.315.7196.

10. Riaz H, Finlayson A, Bashir S, Hussain S, Mahmood S, Malik F, et al. Prevalence of Vitamin D deficiency in Pakistan; implications for the future. Expert Rev ClinPharmacol. 2015. [Epub ahead of print]

11. Ladero JM, Torrejón MJ, Sánchez-Pobre P, Suárez A, Cuenca F, de la Orden V, et al. Vitamin D deficiency and vitamin D therapy in chronic hepatitis C. Ann Hepatol. 2013; 12(2):199204.

12. Cholongitas E, Theocharidou E, Goulis J, Tsochatzis E, Akriviadis E, Burroughs K. Review article: the extra-skeletal effects of vitamin D in chronic hepatitis $\mathrm{C}$ infection. Aliment PharmacolTher. 2012; 35(6):634-46.

13. Petta S, Grimaudo S, Tripodo C, Cabibi D, Calvaruso M, Di Cristina A, Guarnotta C, Macaluso FS, Minissale MG, Marchesini G, Craxì A. The hepatic expression of vitamin D receptor is inversely associated with the severity of liver damage in genotype 1 chronic hepatitis $C$ patients. The Journal of Clinical Endocrinology \& Metabolism. 20151; 100(1):193200.
14. Paternostro R, Wagner D, Reiberger T, Mandorfer M, Schwarzer R, Ferlitsch M, Trauner M, Peck-Radosavljevic M, Ferlitsch A. Low 25-OH-vitamin D levels reflect hepatic dysfunction and are associated with mortality in patients with liver cirrhosis. Wiener Klinische Wochenschrift. 2017; 129(12):8-15.

15. Kitson MT, Sarrazin C, Toniutto P, Eslick GD, Roberts SK. Vitamin D level and sustained virologic response to interferonbased antiviral therapy in chronic hepatitis C: a systematic review and meta-analysis. Journal of hepatology. 2014; 61(6):1247-52.

16. Petta $\mathrm{S}$, Cammà C, Scazzone $\mathrm{C}$, Tripodo $\mathrm{C}$, Di Marco V, Bono A et al. Low vitamin D serum level is related to severe fibrosis and low responsiveness to interferon-based therapy in genotype 1 chronic hepatitis C. Hepatology. 2010;51(4):1158-67.

17. Clark PJ, Thompson AJ, Vock DM, Kratz LE, Tolun AA, Muir AJ et al. Hepatitis $\mathrm{C}$ virus selectively perturbs the distal cholesterol synthesis pathway in a genotype-specific manner. Hepatology. 2012; 56(1):49-56.

18. Ladero JM, Torrejón MJ, Sánchez-Pobre P, Suárez A, Cuenca F, de la Orden V et al. Vitamin D deficiency and vitamin D therapy in chronic hepatitis C. Ann Hepatol. 2013; 12(2):199204.

19. Jin CN, Chen JD, Sheng JF. Vitamin D deficiency in hepatitis $\mathrm{C}$ virus infection: what is old? What is new? European journal of gastroenterology \& hepatology. 2018; 30(7):741-6. 